\title{
Conventional and In Vitro Propagation of Lechenaultia macrantha (Goodeniaceae)
}

\author{
Guochen K. Png', Katherine S. Downes, and Beng H. Tan \\ Department of Environment and Agriculture, Curtin University, Building \\ 311, Kent Street, GPO Box U1987, Perth, WA 6845, Australia
}

Additional index words. dormancy, micropropagation, ornamental Australian endemic, seed germination, stem cuttings, tissue culture

\begin{abstract}
Lechenaultia macrantha $\mathrm{K}$. Krause (Goodeniaceae) is a species with great horticultural potential that is endemic to the sandy and gravelly soils of central, southwestern Australia. The effectiveness of several conventional and in vitro propagation techniques were assessed. Seeds possessed non-deep physiological dormancy, and a combination of seed nicking and imbibition in $10 \%$ (v/v) smoke water for 24 hours resulted in $81 \%$ germination after 33 days of incubation. Softwood stem cuttings produced adventitious roots readily without the need for exogenous auxin application. In vitro microcuttings produced shoots in response to cytokinins. However, optimal or suboptimal cytokinin concentrations resulted in hyperhydric shoots, which poses an obstacle to successful micropropagation. The use of auxin was necessary for the initiation of adventitious roots in vitro. This information will assist in the horticultural development of this species.
\end{abstract}

Lechenaultia macrantha K. Krause (Goodeniaceae), commonly known as the Wreath Lechenaultia, is endemic to central, southwestern Australia (Morrison, 1992). Owing to its intriguing "wreath-like" form, L. macrantha is one of the main wildflower attractions of the Shires of Morawa and Mullewa in Western Australia (WA) and is of interest horticulturally (Wrigley and Fagg, 2003). Although the species is not currently classified as threatened (Western Australian Herbarium, 1998), increasing pressures from illegal collection (D.G. Williams, personal communication; Kelly et al., 2003), agriculture (Hobbs, 1993), and associated land fragmentation (Wilcox and Murphy, 1985) may pose threats to the species' long-term survival. Despite its outstanding ornamental horticultural potential, there is a dearth of knowledge regarding the propagation of this species. Any research leading to its successful propagation will contribute to its horticultural development as well as its conservation.

Seed propagation is one of the most costefficient means of multiplying plants if there is a sufficient supply of good quality seeds

\footnotetext{
Received for publication 5 Sept. 2012. Accepted for publication 8 Nov. 2012.

We thank Lydia Kupsky, Peter Mioduszewski, William Parkinson, Kevin Seaton (DAFWA), Chris McMullan (DAFWA), Joyce Ho, and Minh Hien To for logistic/technical assistance, the Shire of Morawa WA for access to plants, and Byron Lamont, Christine Cooper, and Kelly Shepherd for comments on the manuscript. Stem cuttings were collected with permission from the Western Australia Department of Environment and Conservation (license no. SW014016).

${ }^{1}$ To whom reprint requests should be addressed; e-mail g.png@student.curtin.edu.au.
}

and those seeds can be germinated. The germination of many taxa within the Goodeniaceae is constrained by poorly understood dormancy mechanisms and/or germination stimulant requirements (Bell et al., 1993; Merritt et al., 2007). To better understand how to overcome dormancy, it is instructive to determine the type of seed dormancy (Baker et al., 2005a) using a widely accepted classification system proposed by Baskin and Baskin (2004).

The seeds of $L$. macrantha are enclosed in a hard woody endocarp and are often referred to as "woody articles" (Jabaily et al., 2012). If these seeds are unable to imbibe water, they have physical dormancy. If they can imbibe water, they may possess a physiological block that reduces the capacity of the embryo to push through the surrounding hard woody endocarp (Baskin and Baskin, 2004). Some methods used to overcome physical dormancy include removal or scarification of the outer layers of the seed and acid scarification (Baskin and Baskin, 2004). Seeds with non-deep physiological dormancy can also be artificially induced to germinate by seedcoat nicking or more naturally through dry afterripening, cold/warm stratification (Baskin and Baskin, 2004), and/or wet/dry alternations (Baker et al., 2005b). Smoke application is another method that has enhanced the germination of many WA species, including several closely related Goodeniaceae species (Dixon et al., 1995).

Vegetative propagation through stem cuttings is a commercially important technique used to produce large numbers of clones of plants in horticultural systems (Dawson and King, 1994). However, the use of stem cuttings is generally more costly than seed propagation because additional infrastructure (e.g., fog or mist systems) is required to protect and nurture the cuttings to enhance survival and encourage growth. Additionally, many woody Australian species do not form adventitious roots on stem cuttings readily, which hinders propagation (Dawson and King, 1994). Auxins are used in vegetative propagation to stimulate adventitious root growth. Because the ratios of endogenous plant growth regulators vary between different stem tissues, application of excessive levels of exogenous auxin to the cuttings may suppress the growth of shoots and/or roots (Hartmann et al., 2002). Therefore, it is necessary to consider the concentration of exogenous auxin applied to stem cuttings to optimize propagation success.

Shoot micropropagation, the most common in vitro propagation system, provides an alternative method of propagating plants that is time-consuming or difficult to propagate otherwise (Offord et al., 2009). The feasibility of shoot micropropagation of $L$. macrantha has yet to be investigated. The provision of exogenous cytokinins to the explant through the culture medium at the shoot multiplication stage stimulates the formation of microshoots (Hartmann et al., 2002). Thidiazuron (TDZ; N-phenyl-N-1, 2, 3-thiadiazol-5-ylurea), a potent synthetic diphenylurea cytokinin, exhibits a higher cytokinin activity and persistency than synthetic aminopurine cytokinins at equimolar concentrations and initiates microshoots that are unresponsive to aminopurine cytokinins such as kinetin [N(s-furnylmethyl)-1H-purin-6-amine] and 6benzyladenine (BA) in other species (Hutteman and Preece, 1993; Lu, 1993). Although increasing cytokinin concentration is generally associated with increasing shoot initiation, it also increases callus growth, which promotes the indirect development of adventitious shoots and reduces the direct development of axillary microshoots (Hutteman and Preece, 1993). The high rate of adventitious shoot production is undesirable where clonal fidelity is required, because adventitiously formed shoots may be somaclonal variants (Hutteman and Preece, 1993). Supraoptimal levels of cytokinin activity also adversely affect the multiplication process through the inhibition of shoot elongation (Hutteman and Preece, 1993; Lu, 1993); the intensification of callusing (Hutteman and Preece, 1993); the inhibition of root development in the root formation stage (Hutteman and Preece, 1993; Lu, 1993); and the elevation of hyperhydricity in a concentration-dependent manner (Debergh et al., 1992; Ivanova et al., 2006; Kevers et al., 2004). Hyperhydricity (previously known as vitrification) refers to the malformed and watery appearance of plantlets resulting from abnormal physiological development, which impedes the multiplication, growth, and acclimatization of plantlets, resulting in significant losses in micropropagation (Debergh et al., 1992). Because shoot formation response to the different cytokinins is species-specific, it is necessary to assess the efficacy and quality of L. macrantha microshoots produced by the different cytokinin types and concentrations.

In micropropagation, a high auxin-tocytokinin concentration ratio is typically used 
in the culture medium to induce root formation (Hartmann et al., 2002). However, supraoptimal concentrations of auxin can suppress root growth (de Klerk, 2000; Riov and Yang, 1989). Hence, investigating the optimal auxin concentration required for $L$. macrantha root induction would assist in the micropropagation of this species.

The aims of this study were to enhance the ability to propagate $L$. macrantha for horticultural and conservation purposes by comparing the relative effectiveness of some conventional (seeds and stem cuttings) and in vitro (micropropagation) propagation techniques and to determine the optimum conditions for these techniques.

\section{Materials and Methods}

Seed source. Seeds of L. macrantha were purchased from Nindethana Seed Service (Albany, WA). They were collected in the summer of 2005-06 from Paynes Find, WA, and stored within a sealed container, at $\approx 15$ to $20{ }^{\circ} \mathrm{C}$ before the commencement of experiments in 2011.

Dormancy classification. To determine whether L. macrantha seeds possess physical dormancy, the percentage increase in seed weight between two replicates of 50 scarified and 50 non-scarified seeds imbibed in deionized water, over periods of 24 and $48 \mathrm{~h}$, at $\approx 24{ }^{\circ} \mathrm{C}$ were compared. Seeds were scarified between two layers of 60 -grit sandpaper (FH Prager, New South Wales, Australia) by hand. Seeds of each treatment group were weighed before imbibition, imbibed for the specified duration, then blotted with paper towels to remove excess moisture before reweighing. Forty seeds were then dissected longitudinally and examined under a dissecting microscope to elucidate embryo differentiation, relative size, morphology and to determine whether endosperm was present.

Germination. The six germination treatments undertaken were: 1) control-no treatment; 2) scarification-scarifying seeds between two layers of 60-grit sandpaper (FH Prager) by hand to reduce the thickness of the woody endocarp; 3) chemical scarification-placing seeds in $98 \%(\mathrm{w} / \mathrm{v})$ sulfuric acid $\left(\mathrm{H}_{2} \mathrm{SO}_{4}\right)$ for $25 \mathrm{~min}$ and then rinsing seeds under deionized water for $1 \mathrm{~h}$; 4) nicking only-cutting through the woody endocarp at one end; 5) smoke water-imbibing seeds in $10 \%(\mathrm{v} / \mathrm{v})$ 'Seed Starter' smoke water for 24 h (purchased from Botanic Gardens and Parks Authority, Perth, Australia, in 2003 and stored at $4{ }^{\circ} \mathrm{C}$ before use); and 6) a combination of smoke water and nicking-imbibing seeds in smoke water for $24 \mathrm{~h}$ followed by nicking. Each treatment had six replicates, and each replicate consisted of 50 seeds. Before each treatment, seeds were surface-sterilized by soaking in a $0.5 \%(\mathrm{v} / \mathrm{v}) \mathrm{NaOCl}$ solution containing one drop of the surfactant Tween80 for 5 min before rinsing three times in sterile deionized water. Apart from the sulfuric acid treatment, all treatments were undertaken in a laminar airflow cabinet to maintain sterility. The deionized water, 'Seed Starter' smoke water, filter paper, and vermiculite were autoclaved before use. After treatment, seeds of each replicate were placed in a sterile petri dish on top of two layers of moistened filter paper on a vermiculite substratum. Petri dishes were wrapped in foil to impose darkness as per Dixon et al. (1995) and placed in a room with an ambient temperature maintained at $\approx 24^{\circ} \mathrm{C}$. This temperature was used for incubation as it is between the temperature ranges recommended by Bell et al. $\left(1995 ; 15\right.$ to $\left.23{ }^{\circ} \mathrm{C}\right)$ and Merritt $\left(2006 ; 25\right.$ to $\left.35^{\circ} \mathrm{C}\right)$ for the germination of species occurring within southwestern Australia and the semiarid, midwest-northern regions of WA, respectively, and this species occurs between these two regions. Germination was monitored every $3 \mathrm{~d}$ for $33 \mathrm{~d}$.

At the conclusion of the germination trials, cut and tetrazolium seed viability tests were performed on all of the remaining nongerminated seeds. Seeds were nicked, placed in a petri dish on a piece of filter paper moistened with $1 \%(\mathrm{w} / \mathrm{v})$ 2,3,5-triphenyl$2 \mathrm{H}$-tetrazolium chloride in phosphate buffer solution ( $\mathrm{pH} 7.0$ ), and incubated in the dark in an oven at $37^{\circ} \mathrm{C}$ for $24 \mathrm{~h}$. Seeds that were aborted, wood-filled, unstained, unevenly, or faintly stained were considered inviable; seeds completely stained red or pink were scored as viable. Germination was expressed as a percentage of viable seeds.

Stem cuttings. Softwood stem cuttings were randomly collected from at least 20 individual L. macrantha plants at Morawa (lat. $29^{\circ} 7^{\prime} 47.63^{\prime \prime} \mathrm{S}$, long. $115^{\circ} 56^{\prime} 3.17^{\prime \prime} \mathrm{E}$ ), WA. These cuttings were taken in late Winter 2011 before flowering. Cuttings were placed between layers of wet paper and put in an insulated cooler to reduce water stress during transfer to the glasshouse at the Department of Agriculture and Food, Western Australia (DAFWA), South Perth. These cuttings were treated with indole-3-butyric acid (IBA) at concentrations of 0 (control), 1500, and 3000 $\mathrm{mg} \cdot \mathrm{L}^{-1}$ to determine whether an exogenous application of IBA was required for and/or enhanced rooting. The synthetic auxin IBA is stable, non-phytotoxic over a wide range of concentrations and more potent than other types of auxin (Geneve and Heuser, 1982). The $1500-\mathrm{mg} \cdot \mathrm{L}^{-1}$ application rate is within the recommended range for softwood cuttings (Hartmann et al., 2002). Applications of $3000 \mathrm{mg} \cdot \mathrm{L}^{-1}$ exceed the recommended rates for softwood cuttings (Hartmann et al., 2002) but were used because many Australian plants require higher IBA concentrations (Dawson and King, 1994). Cuttings measuring $\approx 5 \mathrm{~cm}$ were disinfected by soaking in $0.5 \%(\mathrm{v} / \mathrm{v})$ $\mathrm{NaOCl}$ for $1 \mathrm{~min}$ before rinsing three times in deionized water. Leaves on the stems were trimmed to reduce water stress. The lower $2 \mathrm{~cm}$ of the stem cuttings was dipped into deionized water, Clonex ${ }^{\circledR}$ Green $\left(1500 \mathrm{mg} \cdot \mathrm{L}^{-1}\right.$ IBA gel; Growth Technology, WA), or Clonex ${ }^{\circledR}$ Purple (3000 mg. $\mathrm{L}^{-1}$ IBA gel; Growth Technology, WA). Sixty-four stems were prepared for each concentration and divided into eight punnets filled with a rooting mix comprised of moist peat, perlite, and polystyrene beads in the ratio of $2: 1: 1$ by volume. Punnets were placed on a propagation bench (bottom heat maintained at $\approx 27^{\circ} \mathrm{C}$ ) in a glasshouse maintained at $\approx 99 \%$ humidity. Overhead finemisters were programed to spray for $1 \mathrm{~min}$ at 5-min intervals. After 6 weeks, the rooting response, number of roots produced per stem, and the root length per root (measured to the nearest $0.02 \mathrm{~mm}$ using a pair of electronic calipers) of stems in each of the three IBA concentrations were assessed.

Stem anatomy. Transverse slices from the middle and the tip of fresh stem cuttings were obtained by hand sectioning, and lignified cells were stained with one drop of $5 \%(\mathrm{w} / \mathrm{v})$ phloroglucinol together with one drop of concentrated hydrochloric acid. Slides were observed microscopically to determine whether sclerenchyma was present as a potential barrier for root emergence and to determine the type of thickening (primary or secondary growth). This information is essential to verify the physiological nature of the stems that are readily available for cuttings and to relate it to the rooting results of the cuttings treated with different IBA concentrations.

In vitro shoot culture stock. Microcutting explants used for in vitro experiments were taken from seedlings obtained from the germination experiments, surface-sterilized by soaking in a $0.5 \%(\mathrm{v} / \mathrm{v}) \mathrm{NaOCl}$ solution containing one drop of the surfactant Tween- 80 for $30 \mathrm{~s}$, before rinsing three times in sterile deionized water, then maintained on an establishment culture medium (ECM) developed for $L$. macrantha microshoot propagation by trial and error (B.H. Tan, unpublished data). ECM consisted of $4.4 \mathrm{~g} \cdot \mathrm{L}^{-1} \mathrm{M} 6899$ Murashige and Skoog basal salts with minimal organics (MSMO; Sigma Co., Castle Hill, New South Wales, Australia; Murashige and Skoog, 1962) supplemented with $0.024 \mathrm{mg} \cdot \mathrm{L}^{-1}$ iron chelate [Fe(EDTA) $)^{-}$, 2\% (w/v) sucrose, $0.2 \mathrm{mg} \cdot \mathrm{L}^{-1}$ kinetin, and solidified with $1 \%(\mathrm{w} / \mathrm{v})$ agar (Sigma Co., Castle Hill, New South Wales, Australia). Before the addition of agar, the medium was adjusted to $\mathrm{pH} 5.8$, then autoclaved at $121{ }^{\circ} \mathrm{C}$ and $100 \mathrm{kPa}$ for $20 \mathrm{~min}$, before pouring into vented $250-\mathrm{mL}$ micropropagation jars. Stock cultures were placed at $\approx 24{ }^{\circ} \mathrm{C}$ under a daily $12 \mathrm{~h} \mathrm{light} / 12 \mathrm{~h}$ dark photoperiod at $\approx 60 \mu \mathrm{mol} \cdot \mathrm{m}^{-2} \cdot \mathrm{s}^{-1}$ photosynthetic photon flux density (PPFD; supplied by equal numbers of Sylvania GroLux $36 \mathrm{~W}$ and Philips $36 \mathrm{~W}$ Cool White fluorescent light tubes). Shoots were maintained and subcultured at four weekly intervals on the semisolid ECM.

In vitro shoot multiplication. Three cytokinins were compared for their effectiveness in inducing $L$. macrantha shoot multiplication. The cytokinin content of the ECM was varied with $0.02 \mathrm{mg} \cdot \mathrm{L}^{-1} \mathrm{TDZ}, 0.02 \mathrm{mg} \cdot \mathrm{L}^{-1}$ $\mathrm{BA}$, or $0.2 \mathrm{mg} \cdot \mathrm{L}^{-1}$ kinetin, then autoclaved and poured into the same type of jars as for the shoot culture stock. Four shoot microcuttings of $\approx 2 \mathrm{~cm}$ were placed into the semisolid medium in each jar and placed under the same temperature and light conditions as the shoot culture stock. Each treatment jar was replicated six times. After 6 weeks, the number of microcuttings that produced 
microshoots (axillary, adventitious, or both) was recorded. Microshoots were measured to the nearest $0.02 \mathrm{~mm}$ using a pair of electronic calipers; qualitatively scored for hyperhydricity on an ordinal scale of 1 (non-hyperhydric), 2 (least hyperhydric) to 5 (most hyperhydric); and microscopically observed for the presence of dysfunctional stomata to verify hyperhydricity.

In vitro rooting. Three IBA concentrations: 0 (control), 1.0 , and $5.0 \mathrm{mg} \cdot \mathrm{L}^{-1}$, were assessed for their effectiveness in inducing in vitro rooting of microcuttings. IBA is the most commonly used auxin for the root induction of microcuttings, because it is the least heat-labile (Nissen and Sutter, 1990). The cytokinin content of the ECM was replaced with auxin concentrations of 0.0 , 1.0 , or $5.0 \mathrm{mg} \cdot \mathrm{L}^{-1} \mathrm{IBA}$, then autoclaved and poured into the same type of jars as for the shoot culture stock. Four shoot microcuttings of $\approx 2 \mathrm{~cm}$ were placed into the semisolid medium in each jar and placed at $\approx 24{ }^{\circ} \mathrm{C}$ under a daily $12 \mathrm{~h}$ light $/ 12 \mathrm{~h}$ dark photoperiod at $\approx 20 \mu \mathrm{mol} \cdot \mathrm{m}^{-2} \cdot \mathrm{s}^{-1}$ PPFD. Each treatment jar was replicated three times. After 4 weeks, the rooting response and the number of roots produced per stem and the root length (measured to the nearest $0.02 \mathrm{~mm}$ ) per root produced at the three IBA concentrations were assessed.

Statistical analyses. One-way analysis of variance (ANOVA) tests were performed on final germination percentages after tetrazolium seed viability tests; the number of roots produced per stem cutting and its root length (mm) per root after 6 weeks; the number of microshoots produced, microshoot length $(\mathrm{mm})$ per microcutting, degree of hyperhydricity exhibited by axillary, adventitious, and total microshoots among the three cytokinin types after 6 weeks; and the number of roots produced in vitro per stem and root length $(\mathrm{mm})$ per root after 4 weeks.

$\chi^{2}$ tests for associations were performed on the rooting response (rooted and nonrooted) of stem cuttings to the IBA concentrations after 6 weeks, the shooting response (produced shoots and recalcitrant) of stem microcuttings to the three types of cytokinins after 6 weeks, and the rooting response (rooted and non-rooted) of stem microcuttings to the IBA concentrations after 4 weeks.

All percentage data were arcsin square root-transformed before ANOVA tests. Tukey's

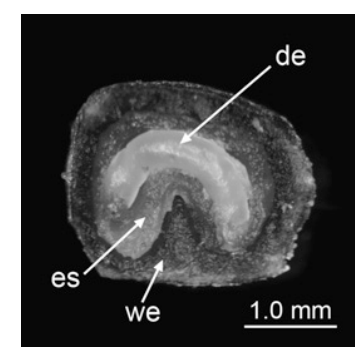

Fig. 1. Image of a typical Lechenaultia macrantha seed/'woody article' sectioned longitudinally contains a well-developed embryo (de), surrounded by a layer of endosperm (es), and woody endocarp (we). post hoc test was also conducted if a significant effect was detected in any ANOVA tests. Differences were regarded as statistically significant if $P<0.05$. All statistical analyses were conducted using SPSS Statistics 17.0 (SPSS Inc., Chicago, IL). Means are presented with SES.

\section{Results}

Dormancy classification. Weight increases of scarified and unscarified seeds after $24 \mathrm{~h}$ of imbibition in deionized water were $9.9 \% \pm$ $0.4 \%$ and $10.8 \% \pm 1.1 \%$, respectively. After $48 \mathrm{~h}$ of imbibition, the weight increases were $9.6 \% \pm 0.3 \%$ and $10.3 \% \pm 0.1 \%$, respectively. These results indicate that the endocarp layer is water-permeable.

All embryos of filled seeds were large (relative to seed size) and well developed (Fig. 1). Endosperm was also present in these seeds (Fig. 1). Embryos could be described as curved linear according to the morphology classification of Martin (1946; Fig. 1).

Germination. Total seed viability in the control after the trial was $35.3 \% \pm 2.2 \%$. The combined treatment of smoke water imbibition followed by nicking produced the highest level of germination $(80.7 \% \pm 3.9 \%$, as a percentage of filled and viable seeds) out of the six treatments tested followed by the nicking treatment alone $(49.4 \% \pm 4.0 \%$; Fig. 2). The cumulative germination of the combined treatment after $33 \mathrm{~d}$ was significantly greater than that of the nicking treatment alone $\left(F_{1,10}=27.6, P<0.001\right.$; Fig. 2$)$. Furthermore, the time taken for $50 \%$ of the seeds to germinate in the combined (smoke water + nicking) treatment $(11 \mathrm{~d})$ was less than that of the nicking treatment $(33 \mathrm{~d}$ or greater; Fig. 2).

Stem cuttings. The rooting response of surviving stems after 6 weeks was not associated with the IBA concentrations tested (Table 1). There were no significant differences in the mean number of roots and mean root length per rooted stem among the three IBA concentration levels tested (Table 1).

Stem anatomy. Transverse sections of the stem close to the tip possessed an anatomy typical of a young, herbaceous, dicotyledonous plant with distinct vascular bundles organized in a ring and lacking secondary tissues (Fig. 3A). Transverse sections of the midstem possessed a thin continuous xylem and a thin discontinuous sclerenchyma surrounding the vascular tissues (Fig. 3B). No cork or cork cambium was present on the outer cortex and limited secondary growth was present in the midsections (Fig. 3B).

In vitro shoot multiplication. The shoot proliferation response of microcuttings to the three types of cytokinin was independent of the cytokinins tested $\left(\chi^{2}=4.78, P=0.092\right)$ with 16,10 , and 12 stems responding to the $0.02 \mathrm{mg} \cdot \mathrm{L}^{-1} \mathrm{BA}, 0.2 \mathrm{mg} \cdot \mathrm{L}^{-1}$ kinetin, and 0.02 $\mathrm{mg} \cdot \mathrm{L}^{-1} \mathrm{TDZ}$ treatments, respectively. Fewer than two axillary shoots were produced per stem in each of the three cytokinin treatments (Fig. 4A). BA produced both the highest number of adventitious microshoots (on average over eight shoots per stem) and total microshoots per stem (Fig. 4A). There was no significant difference in the length of axillary microshoots produced among the three cytokinin treatments, but the adventitious microshoots produced were shorter in the BA treatment than in either the TDZ or kinetin treatments (Fig. 4B). All the microshoots produced were hyperhydric (Fig. 4C). There was no significant difference in the degree of hyperhydricity of axillary microshoots produced among the three cytokinin treatments, but the adventitious microshoots produced by the BA treatment were more hyperhydric than those in either the TDZ or kinetin treatments (Fig. 4C).

In vitro rooting. No roots were produced in the control treatment (Table 2). The 1.0$\mathrm{mg} \cdot \mathrm{L}^{-1}$ IBA treatment had the highest number of microcuttings that produced roots followed by the $5.0 \mathrm{mg} \cdot \mathrm{L}^{-1}$ IBA treatment

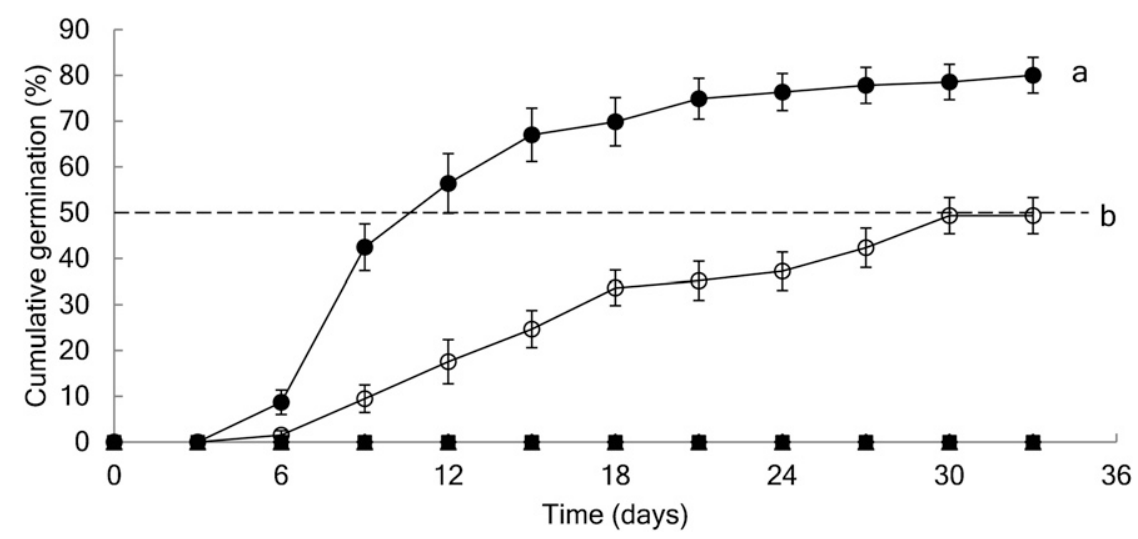

Fig. 2. Cumulative Lechenaultia macrantha germination (mean $\pm \mathrm{SE}$ ) of control $(\square), 10 \%$ smoke water $(\square)$, combination of $10 \%$ smoke water + nicking $(\bigcirc)$, nicking only $(\bigcirc)$, concentrated sulfuric acid $(\triangle)$, and sandpaper scarification $(\nabla)$ treatments over a period of $33 \mathrm{~d}$ of incubation at $\approx 24{ }^{\circ} \mathrm{C}$. Germination was expressed as a percentage of viable seeds of the respective treatments. Different letters indicate significant differences $\left(F_{1,10}=27.6, P<0.001\right)$ between final germination percentages of the combination and nicking only treatments after $33 \mathrm{~d}$; no recorded germination in other treatments. The broken line indicates $50 \%$ cumulative germination. 
Table 1. Effect of IBA concentration on the rooting of Lechenaultia macrantha softwood cuttings after 6 weeks.

\begin{tabular}{lccr}
\hline $\begin{array}{l}\text { IBA concn } \\
\left(\mathrm{mg} \cdot \mathrm{L}^{-1}\right)\end{array}$ & $\begin{array}{c}\text { No. of stems } \\
\text { rooted/surviving }\end{array}$ & $\begin{array}{c}\text { No. of roots per } \\
\text { rooted stem }\end{array}$ & $\begin{array}{c}\text { Mean root } \\
\text { length }(\mathrm{mm})^{\mathrm{y}}\end{array}$ \\
\hline 0 (control) & $34 / 44$ & $7.5 \pm 1.0$ & $6.35 \pm 0.56$ \\
1500 & $32 / 36$ & $6.9 \pm 0.9$ & $5.01 \pm 0.48$ \\
3000 & $29 / 37$ & $6.2 \pm 0.7$ & $5.98 \pm 0.52$ \\
Significance & $\chi^{2}=2.03$ & $F_{2,92}=1.76$ & $F_{2,92}=0.480$ \\
& $P=0.362$ & $P=0.178$ & $P=0.620$ \\
\hline
\end{tabular}

${ }^{\mathrm{z}}$ Compared using the $\chi^{2}$ test for associations.

${ }^{\mathrm{y}}$ Compared using one-way analysis of variance.

$\mathrm{IBA}=$ indole-3-butyric acid.
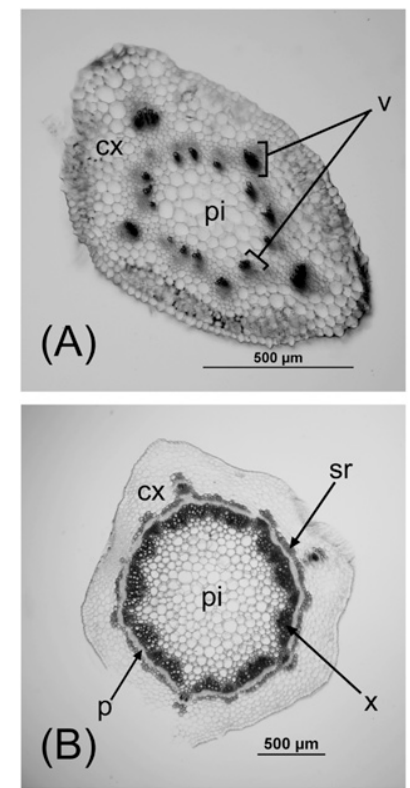

Fig. 3. Transverse sections of (A) tip and (B) midstem of representative Lechenaultia macrantha stems. Lignified cells stained with phloroglucinol. $\mathrm{sr}=$ sclerenchyma ring; $\mathrm{x}=\mathrm{xylem} ; \mathrm{p}=$ phloem tissues; $\mathrm{v}=$ vascular bundle; $\mathrm{cx}=$ cortex; $\mathrm{pi}=$ pith.

(Table 2). There were no significant differences in the number of roots and root length per rooted stem between the $1.0 \mathrm{mg} \cdot \mathrm{L}^{-1}$ and 5.0-mg. $\mathrm{L}^{-1}$ IBA treatments (Table 2). Investigations involving ex vitro acclimatization and establishment were not conducted because all in vitro shoots produced had moderate to high levels of hyperhydricity.

\section{Discussion}

Lechenaultia macrantha is a plant of immense horticultural interest and potential as a result of its attractive growth form (Wrigley and Fagg, 2003). Establishing effective propagation methods will facilitate both ex situ conservation and commercial propagation of this species, thus reducing the pressures of illegal collection, which currently plagues this species (D.G. Williams, personal communication).

Seeds within the Goodeniaceae are difficult to germinate (Merritt et al., 2007). According to Baskin and Baskin (2004), knowing the dormancy type of seeds can assist in determining how to overcome dormancy. The well-developed embryos of Lechenaultia macrantha seeds discount the possibility of morphological dormancy (Baskin and Baskin, 2004). Seeds were water-permeable and hence not physically dormant either according to the classification system of Baskin and Baskin (2004). The absence of physical and morphological dormancy, and negligible seed germination in the absence of nicking, suggests some form of physiological dormancy. These features, together with the fact that seeds germinate after nicking, indicates that this species possesses non-deep physiological dormancy. Indeed, non-deep physiological dormancy is the most widespread form of dormancy of species in Mediterraneantype climates (Nikolaeva, 2004), where this species is distributed. Such dormancy can be alleviated by a period of afterripening or cold/warm stratification at appropriate temperatures (Baskin and Baskin, 2004). The storage conditions of these seeds over a number of years $\left(15\right.$ to $\left.20^{\circ} \mathrm{C}\right)$ did not alleviate dormancy, as found by Turner et al. (in press), for a number of other WA species.

Resistance by the woody endocarp layer to radicle emergence is a key germination constraint in $L$. macrantha, which can be viewed as a form of mechanical dormancy because the embryo has low "push power" to tissue layers. Only treatments involving nicking through the woody endocarp were successful at inducing germination. Although acid and sandpaper scarification treatments would have weakened the woody endocarp layer, they were ineffective at inducing germination, because they did not diminish the physical barrier sufficiently for radicle emergence. Although seed nicking was effective at lowering resistance of the woody endocarp, it is time-consuming and impractical when compared with sandpaper and acid scarification techniques in a nursery scenario (Roche et al., 1997). Although sandpaper scarification was ineffective in this study, scarification using a commercial scarification machine could be investigated further (Schatral, 1995). The other form of scarification tested, acid scarification, failed to promote germination and had an adverse effect on seed viability (data not shown), although with a shorter exposure time (i.e., less than $25 \mathrm{~min}$ ), this approach may still prove to be effective.

In contrast to Dixon et al. (1995), in which L. macrantha seeds produced low levels of overcome the constraints of the surrounding germination $(\approx 25 \%)$ when treated with smoke, smoke alone did not promote any germination in this study. Germination stimulation by smoke was possibly prevented by the presence of non-deep physiological dormancy in our study. In many species, dormancy must be alleviated before seeds can respond to smoke (Baker et al., 2005b; Merritt et al., 2007). The storage conditions of the seeds used by Dixon et al. (1995) are unknown but may have reduced dormancy. Although smoke alone did not stimulate germination in this study, seeds that were smoke-treated and nicked germinated more rapidly and produced significantly higher germination rates than nicked seeds without smoke stimulation.

The softwood stem cuttings of L. macrantha produced adventitious roots readily without the aid of exogenous rooting hormones, which is consistent with the findings for stem cuttings of other Lechenaultia species (Morrison and George, 2004). Perhaps most species within the genus could be propagated successfully from stem cuttings. The application of exogenous IBA to stem cuttings had no significant effect on rooting response and quality of adventitious roots produced. This suggests that softwood cuttings of L. macrantha possess sufficient levels of endogenous auxins for adventitious root formation.

Anatomical studies on representative stem cutting material confirmed the classification of the cuttings as softwood. The absence of a thick continuous sclerenchyma in the cortex would permit root initials to push through the cortex and emerge from the stem. Many easy-to-root species lack this anatomical barrier (Beakbane, 1969). Often softwood cuttings suffer from water stress easily (Hartmann et al., 2002), which may be associated with the large proportion of desiccation-prone parenchyma and the thin epidermal cuticle. To improve survival of softwood cuttings, an application of wax-based antitranspirant may be beneficial (Wang et al., 1992).

In vitro microcuttings of $L$. macrantha readily produced shoots when cytokinin was applied. Unlike recalcitrant species, new shoots were initiated by the less potent aminopurinetype, kinetin cytokinin (Hutteman and Preece, 1993; Lu, 1993). Although the BA treatment produced more microshoots than the other cytokinin treatments tested, a large proportion of the microshoots produced by BA were adventitious. This may be the result of the BA concentration being supraoptimal, resulting in enhanced callusing, axillary shoot growth being inhibited, and the promotion of adventitious shoot proliferation (Hutteman and Preece, 1993). Similar shoot multiplication rates produced by the TDZ and establishment culture medium suggest that L. macrantha microcuttings were more responsive to aminopurine-type than diphenylureatype cytokinins. The anomalous higher shoot proliferation response to BA than TDZ was also found in Miscanthus sinensis (Nielsen et al., 1993). In the future, higher kinetin concentrations and lower BA concentrations could be investigated to optimize the rate of 


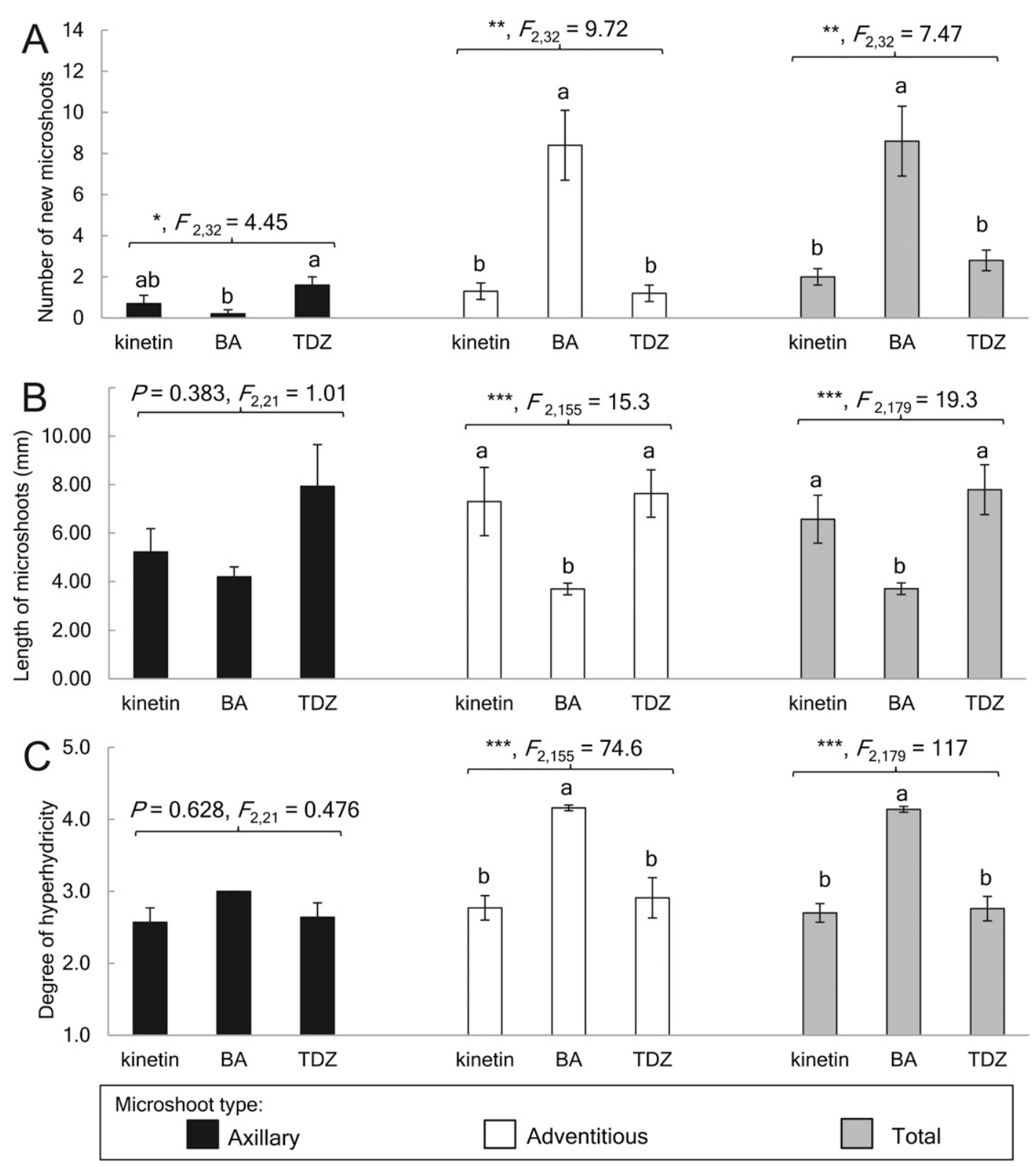

Fig. 4. Comparison of the (A) number of Lechenaultia macrantha microshoots produced per microcutting, (B) mean length of microshoots (mm) produced, and (C) degree of hyperhydricity exhibited by axillary, adventitious and total (axillary + adventitious) microshoots among three cytokinin types $\left(0.2 \mathrm{mg} \cdot \mathrm{L}^{-1}\right.$ kinetin, $0.02 \mathrm{mg} \cdot \mathrm{L}^{-1} \mathrm{BA}$, and $0.02 \mathrm{mg} \cdot \mathrm{L}^{-1} \mathrm{TDZ}$ ). Bars represent sEs. Different letters indicate significant differences (Tukey's honestly significant difference, $P<0.05) . * * *, * * *$ significant at $P<0.05,0.01$, or 0.001 , respectively. $\mathrm{BA}=6$-benzyladenine; TDZ $=$ thidiazuron.

Table 2. Effect of IBA concentration on the in vitro rooting of Lechenaultia macrantha microcuttings after 4 weeks.

\begin{tabular}{lccc}
\hline $\begin{array}{l}\text { IBA concn } \\
\left.\text { (mg. } \mathrm{L}^{-1}\right)\end{array}$ & $\begin{array}{c}\text { No. of stems } \\
\text { rooted/surviving }\end{array}$ & $\begin{array}{c}\text { No. of roots per } \\
\text { rooted stem }\end{array}$ & $\begin{array}{c}\text { Mean root } \\
\text { length }(\mathrm{mm})^{\mathrm{y}}\end{array}$ \\
\hline $0($ Control $)$ & $0 / 12$ & - & - \\
1.0 & $8 / 12$ & $2.8 \pm 0.9$ & $1.32 \pm 0.16$ \\
5.0 & $4 / 12$ & $4.5 \pm 0.9$ & $1.58 \pm 0.14$ \\
Significance & $\chi^{2}=10.0$ & $F_{1,10}=0.813$ & $F_{1,10}=0.178$ \\
& $P=0.007$ & $P=0.389$ & $P=1.09$ \\
\hline
\end{tabular}

${ }^{2}$ Compared using the $\chi^{2}$ test for associations.

${ }^{\mathrm{y}}$ Compared using one-way analysis of variance.

IBA = indole-3-butyric acid.

axillary shoot production if clonal fidelity is imperative. Possibly, the shorter adventitious microshoots produced by the BA treatment compared with the other cytokinin treatments could be the result of the high

cytokinin activity levels of BA, which inhibit shoot elongation (Hutteman and Preece, 1993; Lu, 1993).

Hyperhydric shoots were present in all cytokinin treatments. This is a common problem encountered in the in vitro propagation of Australian plants (Johnson, 1996; Offord and Tyler, 2009). The higher level of hyperhydricity observed in adventitious shoots produced by BA, compared with TDZ or kinetin, was reflective of the supraoptimal BA concentrations used in the culture medium. This was consistent with several studies that demonstrated that the degree of hyperhydricity increases with increasing cytokinin concentrations (Ivanova et al., 2006; Kataeva et al., 1991). Despite the low cytokinin activity levels of TDZ and kinetin treatments used in this study, hyperhydric microshoots produced by these treatments contained dysfunctional leaf stomata that pose a major obstacle to successful hardening of the plantlets (Debergh et al., 1992). The problem 
of hyperhydricity affecting $L$. macrantha is consistent with the findings in the study involving L. pulvinaris (Rossetto et al., 1992). Further studies could be undertaken on cultivating $L$. macrantha on an aerated culture medium because this has reduced hyperhydricity in a number of other species including L. pulvinaris (Rossetto et al., 1992).

The use of auxin is a requisite for the adventitious rooting of $L$. macrantha microcuttings under in vitro conditions. Lechenaultia macrantha microshoots do not possess capacity to initiate adventitious roots on the basal medium alone. The necessity of auxins for rooting $L$. macrantha in vitro corresponds to the in vitro rooting propensities of other species within the genus (Johnson, 1996; Worrall, 1996). Although the concentrations of IBA at $1.0 \mathrm{mg} \cdot \mathrm{L}^{-1}$ and $5.0 \mathrm{mg} \cdot \mathrm{L}^{-1}$ were equally effective at promoting in vitro rooting, the adverse effects caused by supraoptimal auxin concentrations (e.g., shoot inhibition) are only discernible during acclimatization. Therefore, the use of $1.0 \mathrm{mg} \cdot \mathrm{L}^{-1}$ IBA is recommended.

\section{Conclusions}

Lechenaultia macrantha is of immense horticultural interest and potential. We have shown that stem cuttings are an effective method of propagating this species clonally. Stem cuttings rooted easily without the application of exogenous auxins. However, propagation structures required to maintain the predominantly softwood cuttings may be a cost consideration. Seeds of $L$. macrantha are known to be difficult to germinate, but we have shown that these seeds have non-deep physiological dormancy, which will assist in the future identification of effective germination methods. A high percentage of viable seeds can be induced to germinate by imbibing seeds in $10 \%$ smoke water for $24 \mathrm{~h}$ and then nicking them. Unless the woody endocarp resistance to radicle emergence can be efficiently reduced, seed-based propagation by nicking seeds after smoke application is impractical in a scaled-up situation (as in nursery production) because seed nicking is tedious and time-consuming. Methods of alleviating non-deep physiological dormancy in L. macrantha seeds before smoke application such as afterripening or stratification may provide an alternative to nicking and warrants further investigation. Propagation using in vitro techniques is problematic as a result of hyperhydricity of the microshoots, but techniques to reduce hyperhydricity such as aeration could be tested in the future.

\section{Literature Cited}

Baker, K.S., K.J. Steadman, J.A. Plummer, and K.W. Dixon. 2005a. Seed dormancy and germination responses of nine Australian fire ephemerals. Plant Soil 277:345-358.

Baker, K.S., K.J. Steadman, J.A. Plummer, D.J. Merritt, and K.W. Dixon. 2005b. The changing window of conditions that promotes germination of two fire ephemerals, Actinotus leucocephalus (Apiaceae) and Tersonia cyathiflora (Gyrostemonaceae). Ann. Bot. (Lond.) 96:1225-1236.

Baskin, C.C. and J.M. Baskin. 2004. A classification system for seed dormancy. Seed Sci. Res. 14:1-16.

Beakbane, A.B. 1969. Relationships between structure and adventitious rooting. Proc. Intl. Plant Propagators Soc. Annu. Mtg. 19:192201.

Bell, D.T., J.A. Plummer, and S.K. Taylor. 1993. Seed germination ecology in southwestern Western Australia. Bot. Rev. 59:24-73.

Bell, D.T., D.P. Rokich, C.J. McChesney, and J.A Plummer. 1995. Effects of temperature, light and gibberellic acid on the germination of seeds of 43 species native to Western Australia. J. Veg. Sci. 6:797-806.

Dawson, I.A. and R.W. King. 1994. Propagation of some woody Australian plants from cuttings. Austral. J. Exp. Agr. 34:1225-1231.

de Klerk, G.J. 2000. Rooting treatment and the ex vitrum performance of micropropagated plants. Acta Hort. 530:277-288.

Debergh, P., J. Aitken-Christie, D. Cohen, B. Grout, S. Arnold, R. Zimmerman, and M. Ziv. 1992. Reconsideration of the term 'vitrification' as used in micropropagation. Plant Cell Tissue Organ Cult. 30:135-140.

Dixon, K.W., S. Roche, and J.S. Pate. 1995. The promotive effect of smoke derived from burnt native vegetation on seed germination of Western Australian plants. Oecologia 101: 185-192.

Geneve, R.L. and C.W. Heuser. 1982. The effect of IAA, IBA, NAA, 2, 4-D on root promotion and ethylene evolution in Vigna radiata cuttings. J. Amer. Soc. Hort. Sci. 107:202205.

Hartmann, H.T., D.E. Kester, F.T. Davies, and R. Geneve. 2002. Plant propagation: Principles and practices. 7th Ed. Pearson Education, NJ.

Hobbs, R.J. 1993. Effects of landscape fragmentation on ecosystem processes in the Western Australian wheatbelt. Biol. Conserv. 64:193201.

Hutteman, C.A. and J.E. Preece. 1993. Thidiazuron: A potent cytokinin for woody plant tissue culture. Plant Cell Tissue Organ Cult. 33:105-109.

Ivanova, M., O. Novak, M. Strnad, and J. van Staden. 2006. Endogenous cytokinins in shoots of Aloe polyphylla cultured in vitro in relation to hyperhydricity, exogenous cytokinins and gelling agents. Plant Growth Regulat. 50:219230.

Jabaily, R.S., K.A. Shepherd, M.H.G. Gustafsson, L.W. Sage, S.L. Krauss, D.G. Howarth, and T.J. Motley. 2012. Systematics of the AustralPacific family Goodeniaceae - establishing a taxonomic and evolutionary framework. Taxon 61:419-436.

Johnson, K.A. 1996. The application of in vitro technology to Australian native plants (with particular emphasis on the nutritional requirements), p. 3-37. In: Taji, A.M. and R.R. Williams (eds.). Tissue culture of Australian plants. Univ. of New England Printery, New South Wales, Australia.

Kataeva, N.V., I.G. Alexandrova, R.G. Butenko, and E.V. Dragavtceva. 1991. Effect of applied and internal hormones on vitrification and apical necrosis of different plants cultured in vitro. Plant Cell Tissue Organ Cult. 27:149154.

Kelly, C.L., C.M. Pickering, and R.C. Buckley. 2003. Impacts of tourism on threatened plant taxa and communities in Australia. Ecol. Mgt. Restor. 4:37-44.

Kevers, C., T. Franck, R.J. Strasser, J. Dommes, and T. Gaspar. 2004. Hyperhydricity of micropropagated shoots: A typically stress-induced change of physiological state. Plant Cell Tissue Organ Cult. 77:181-191.

$\mathrm{Lu}, \mathrm{C} .1993$. The use of thidiazuron in tissue culture. In Vitro Cell. Dev. Biol. Plant 29:92-96.

Martin, A.C. 1946. The comparative internal morphology of seeds. Amer. Midl. Nat. 36:513-660.

Merritt, D. 2006. Seed storage and testing, p. 5360. In: Sweedman, L. and D. Merritt (eds.). Australian seeds: A guide to their collection, identification and biology. CSIRO Publishing, Victoria, Australia.

Merritt, D.J., S.R. Turner, S. Clarke, and K.W. Dixon. 2007. Seed dormancy and germination stimulation syndromes for Australian temperate species. Austral. J. Bot. 55:336-344.

Morrison, D. and A. George. 2004. The genus Lechenaultia. Curtis's Bot. Mag. 21:106-110.

Morrison, D.A. 1992. Lechenaultia, p. 17-33. In: George, A.S. (ed.). Flora of Australia, Volume 35, Brunoniaceae, Goodeniaceae. Austral. Govt. Publ. Serv., Canberra, Australia.

Murashige, T. and F. Skoog. 1962. A revised medium for rapid growth and bio assays with tobacco tissue cultures. Physiol. Plant. 15:473497.

Nielsen, J.M., K. Brandt, and J. Hansen. 1993. Long-term effects of thidiazuron are intermediate between benzyladenine, kinetin or isopentenyladenine in Miscanthus sinensis. Plant Cell Tissue Organ Cult. 35:173-179.

Nikolaeva, M.G. 2004. On criteria to use in studies of seed evolution. Seed Sci. Res. 14:315-320.

Nissen, S.J. and E.G. Sutter. 1990. Stability of IAA and IBA in nutrient medium to several tissue culture procedures. HortScience 25: $800-802$.

Offord, C.A., E. Bunn, S.R. Turner, K.D. Sommerville, J. Siemon, and S.E. Ashmore. 2009. Tissue culture, p. 109-128. In: Offord, C.A. and P.F. Meagher (eds.). Plant germplasm conservation in Australia: Strategies and guidelines for developing, managing and utilising ex situ collections. Australian Network for Plant Conservation Inc., Canberra, Australia.

Offord, C.A. and J.L. Tyler. 2009. In vitro propagation of Pimelea spicata R.Br (Thymelaeaceae), an endangered species of the Sydney region, Australia. Plant Cell Tissue Organ Cult. 98: 19-23.

Riov, J. and S.F. Yang. 1989. Ethylene and auxinethylene interaction in adventitious root formation in mung bean (Vigna radiata) cuttings. J Plant Growth Regul. 8:131-141.

Roche, S., K.W. Dixon, and J.S. Pate. 1997. Seed ageing and smoke: Partner cues in the amelioration of seed dormancy in selected Australian native species. Austral. J. Bot. 45: 783-815.

Rossetto, M., K.W. Dixon, and E. Bunn. 1992. Aeration: A simple method to control vitrification and improve in vitro culture of rare Australian plants. In Vitro Cell. Dev. Biol. Plant 28:192-196.

Schatral, A. 1995. The structure of the seed in some Western Australian species of the genus Hibbertia (Dilleniaceae). Bot. J. Linn. Soc. 119:257-263

Turner, S.R., K.J. Steadman, S. Vlahos, J.M. Koch, and K.W. Dixon. Seed treatment optimizes benefits of seed bank storage for restorationready seeds: The feasibility of prestorage dormancy alleviation for mine-site revegetation. Restor. Ecol (in press). 
Wang, Y.T., K.H. Hsiao, and L.L. Gregg. 1992. Antitranspirant, water stress, and growth retardant influence growth of Golden Pothos. HortScience 27:222-225.

Western Australian Herbarium. 1998. FloraBaseThe Western Australian flora: Lechenaultia macrantha. Department of Environment and
Conservation, Perth, Australia. 30 June 2012. $<$ http://florabase.dec.wa.gov.au/>.

Wilcox, B.A. and D.D. Murphy. 1985. Conservation strategy: The effects of fragmentation on extinction. Amer. Nat. 125:879-887.

Worrall, R. 1996. Lechenaultia, Family Goodeniaceae, p. 218-227. In: Johnson, K.A. and M. Burchett (eds.). Native Australian plants-Horticulture and uses. Univ. of New South Wales Press, New South Wales, Australia.

Wrigley, J.W. and M. Fagg. 2003. Australian native plants: Cultivation, use in landscaping and propagation. 5th Ed. Reed New Holland, New South Wales, Australia. 